\title{
PENGARUH TACIT DAN EXPLICIT KNOWLEDGE UNTUK MENINGKATKAN KINERJA IKM
}

\author{
Ayu Endah Wahyuni \\ Program Studi Teknik Industri, Fakultas Teknik \\ Universitas Widyatama \\ Bandung, Indonesia \\ ayu.endah@widyatama.ac.id
}

\begin{abstract}
Abstrak
Industri kecil menengah (IKM) di Indonesia belum mampu dalam berdaya saing dan mempertahankan competitive advantage terhadap produk asing. Pemanfaatan tacit knowledge dan explicit knowledge belum maksimal, padahal faktor tersebut menjadi sumber keunggulan bersaing dan kemampuan industri dalam berinovasi. Sementara itu, pertumbuhan produksi IKM belum mencapai target yang diharapkan karena performansi IKM masih rendah, sehingga mempengaruhi produktivitasnya. Akar permasalahan penelitian ini terletak pada optimalisasi tacit knowledge dan explicit knowledge belum maksimal terhadap peningkatan organizational performance pada IKM. Penelitian ini bertujuan untuk menguji dan mengembangkan suatu model dengan mengintegrasikan faktor yang terkait dengan tacit knowledge dan explicit knowledge dalam peningkatan organizational performance. Metode pengumpulan data melalui kuesioner dengan IKM kota Bandung sebagai responden penelitian. Pengolahan data menggunakan metode partial least square path modelling (PLS-PM).
\end{abstract}

Kata kunci: Tacit knowledge dan explicit knowledge organizational performance dan IKM.

\begin{abstract}
Small and medium industries (IKM) in Indonesia have not been able to compete and maintain competitive advantage over foreign products. Utilization of tacit knowledge and explicit knowledge is not maximized, even though these factors are a source of competitive advantage and the ability of the industry to innovate. Meanwhile, the growth of SMI production has not reached the expected target
\end{abstract}

because the performance of SMIs is still low, thus affecting its productivity. The root of the problem of this research lies in the optimization of tacit knowledge and explicit knowledge not yet maximized on improving organizational performance in SMIs. This study aims to test and develop a model by integrating factors related to tacit knowledge and explicit knowledge in improving organizational performance. The method of collecting data through questionnaires with IKM city of Bandung as research respondents. Data processing uses partial least square path modeling (PLS-PM) method.

Keywords: Tacit knowledge and explicit knowledge organizational performance and IKM

\section{Pendahuluan}

Globalisasi membawa dampak ketatnya persaingan di dunia usaha terutama pada industri kecil menengah (IKM) di Indonesia terhadap industri asing. Oleh karena itu, industri kecil menengah (IKM) dituntut untuk memiliki modal berkualitas, daya adaptasi tinggi dan daya saing kuat untuk menghadapi semakin tingginya persaingan di era perdagangan bebas (Kurniawati, 2009).

Berdasarkan neraca perdagangan IndonesiaChina yang cenderung menurun sejak tahun 2010 hingga 2012, yaitu sebesar US\$ 4.7 Miliar di 2010 dan US\$ 3.3 Miliar di 2011, bahkan melonjak hingga US\$ 7.7 Miliar di 2012 (ASEAN Statistic Tahun 2012). Hal ini menunjukkan bahwa, industri nasional mengalami penurunan yang mengakibatkan kemampuan daya saing industri nasional berdampak negatif terhadap sektor industri di Indonesia. Banyak kendala yang dihadapi industri kecil menengah (IKM) dalam berdaya saing, antara lain: terbatasnya akses 
dalam pemberian modal, produktivitas yang rendah dan kekurangan tenaga kerja yang kompeten, serta sistem ekonomi dan organisasi belum mampu menghasilkan lingkungan bisnis yang (Kementerian Perindustrian, 2012). Hal tersebut akan mempengaruhi IKM dalam meningkatkan kinerjanya, dimana kinerja industri kecil menengah (IKM) di Indonesia jauh lebih rendah dibandingkan kinerja IKM di negara maju lainnya yang disebabkan oleh rendahnya pengembangan atau penguasaan ilmu pengetahuan dan teknologi (IPTEK) pada industri kecil menengah (IKM) di Indonesia ( Hermawan, 2012).

IKM harus dapat mengembangkan faktor knowledge dalam bersaing dan meningkatkan kinerjamya. Knowledge diklasifikasikan ke dalam dua jenis yaitu tacit knowledge dan explicit knowledge (Polanyi, 1966). Explicit knowledge merupakan jenis pengetahuan yang mudah dibentuk dan didokumentasikan (Choi \& Lee, 2003). Selain itu, explicit knowledge dapat diwujudkan, dituliskan, di transfer dan disampaikan antar unit organisasi secara lisan atau melalui teknologi informasi, paten dan program komputer (Keskin, 2005). Sedangkan, tacit knowledge merupakan jenis pengetahuan yang melekat dalam pikiran manusia. Oleh karena itu, knowledge yang berada dalam industri kecil menengah (IKM), dimana sebagian besar tacit knowledge melekat didalamnya. Namun, tacit knowledge pada industri kecil menengah (IKM) sulit dirubah dalam bentuk explicit. Oleh sebab itu, tacit knowledge sharing merupakan cara terbaik untuk membantu industri kecil menengah (IKM) dalam meningkatkan kinerjanya melalui cara informal dan sosialisasi antar individunya (Wong dan Radcliffe, 2007).

Dengan demikian, penelitian ini bertujuan untuk mengembangkan model tacit knowledge dan explicit knowledge terhadap kinerja IKM di Indonesia.

\section{STUDi LiteratUR}

Knowledge merupakan suatu hal yang berharga, langka, sulit digantikan dan ditiru, serta menjadi sebuah keunggulan bersaing pada organisasi .Setiap organisasi tidak memiliki pengetahuan yang sama, karena antara organisasi mempunyai sumber daya manusia dan sumber pengetahuan yang berbeda (Kim, 2002).
Zheng (2005) menggambarkan knowledge sebagai gabungan dari pengalaman, nilai, informasi secara kontekstual dan wawasan yang menghasilkan suatu kerangka untuk mengevaluasi dan menggabungkan pengalaman baru dan informasi. Selain itu, knowledge berasal dan diterapkan dalam pikiran manusia. Knowledge pada organisasi tidak hanya diwujudkan dalam bentuk dokumen atau tempat penyimpanan, tetapi pada rutinitas organisasi, proses, praktik dan norma.

Knowledge pada industri kecil menengah (IKM) berperan penting dalam persaingan global. Hal ini dikarenakan knowledge menjadi faktor utama dalam keberhasilan industri kecil menengah (IKM) dan sumber keunggulan bersaing yang berkelanjutan (Gharakhani dan Mousakhani, 2011).

Berdasarkan definisi diatas dapat disimpulkan bahwa knowledge adalah sesuatu yang berharga dan sulit untuk ditiru yang digambarkan dalam bentuk pengalaman, nilai dan informasi, serta berperan penting terhadap keberhasilan dan keunggulan bersaing pada industri kecil menengah (IKM).

Knowledge diklasifikasikan menjadi dua jenis meliputi: tacit knowledge dan explicit knowledge (Polanyi, 1966).

\section{Explicit knowledge}

Explicit knowledge adalah salah satu jenis pengetahuan yang mudah didokumentasikan dan dibentuk (Choi and Lee, 2003). Selain itu, explicit knowledge dapat dibuat, ditulis dan ditransfer diantara unit organisasi secara lisan atau melalui program komputer, paten, diagram dan informasi teknologi (Keskin, 2005).

\section{Tacit Knowledge}

Tacit Knowledge merupakan pengetahuan yang berada dalam pikiran manusia, dapat diungkapkan melalui implementasi kemampuan yang disampaikan dalam bentuk dari learning by doing dan learning by watching (Choi and Lee, 2003).

Tacit Knowledge mengacu pada pengetahuan pribadi yang dimiliki individu dalam bentuk pengalaman, pengetahuan, wawasan, keahlian dan kepercayaan. Jenis pengetahuan ini dapat ditemukan pada pertemuan informal melalui tatap muka, diskusi dan pelaporan (Panahi, 2012).

Nonaka dan Takeuchi (1998) mengungkapkan bahwa tacit Knowledge dapat mewujudkan 
keunggulan bersaing pada perusahaan, dimana aliran tacit ke explicit knowledge akan memberikan keuntungan bagi perusahaan. Sebagian besar knowledge yang terdapat dalam industri kecil menengah (IKM) bersifat tacit (Cohen dan Kaimnekais, 2007). Namun, tacit Knowledge yang berada dalam industri kecil menengah (IKM) sulit untuk diubah ke bentuk explicit. Oleh karena itu, sharing pada tacit knowledge dapat membantu industri kecil menengah (IKM) dalam meningkatkan performansinya.

\section{Hasil dan Pembahasan}

Penelitian ini mengacu pada tacit knowledge yang dimiliki oleh industri kecil menengah (IKM) dalam bentuk pengalaman, pengetahuan, wawasan, keahlian dan kepercayaan yang disampaikan melalui pertemuan informal dengan tatap muka dan diskusi.

Salah satu tujuan penelitian ini adalah merancang variable tacit knowledge dan explicit knowledge serta organizational performance. Hal ini dikarenakan variabel-variabel tersebut berperan penting dalam mendorong daya saing industri kecil menengah (IKM) melalui peningkatan performansi perusahaannya. Dalam mendukung tujuan penelitian ini, model dasar yang digunakan pada penelitian ini adalah model dampak intellectual capital dan tacit knowledge sharing terhadap organizational performance oleh (Ngah dan Razak, 2008). Model ini terdiri dari lima variabel, yaitu human capital, structural capital, relational capital dan tacit knowledge sharing, serta organizational performance. dimana tujuan peneltian tersebut menghasilkan informasi yang akan membantu industri kecil menengah (IKM) dalam mengenali pentingnya berbagi pengetahuan sebagai pendekatan yang digunakan untuk meningkatkan kinerja dan profitabilitas perusahaan (Ngah, 2012).

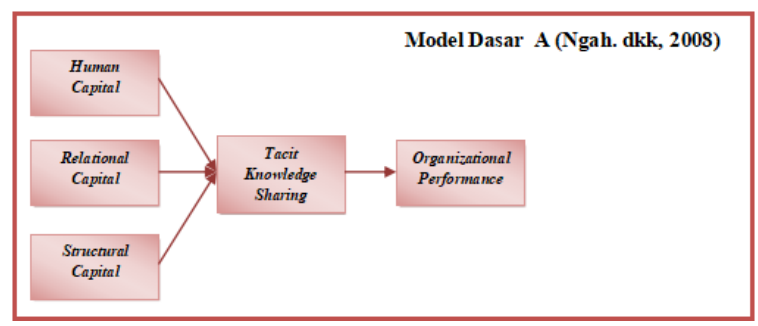

Gambar 1. The Impact Of Intelectual Capital and Tacit Knowledge Sharing on Organizational Performance (Ngah.dkk,2008)

Ada beberapa kontribusi dari penelitian (Wang, dkk, 2014), yaitu mengungkapkan bagimana knowledge sharing membantu meningkatkan performansi perusahaan melalui peran intellectual capital sebagai variabel mediasi. Selain itu, menguji pengaruh dari tacit dan explicit knowledge sharing terhadap komponen intellectual capital, dimana mengarah pada operational dan financial performance. Kemudian, peneltian ini berkontribusi pada knowledge-based view (KBV) oleh studi empiris mengenai hubungan antara knowledge sharing, intellectual capital dan firm performance. Dengan demikian, tujuan penelitian (Wang, dkk, 2014), yaitu menyempurnakan dan memperluas penelitian sebelumnya.

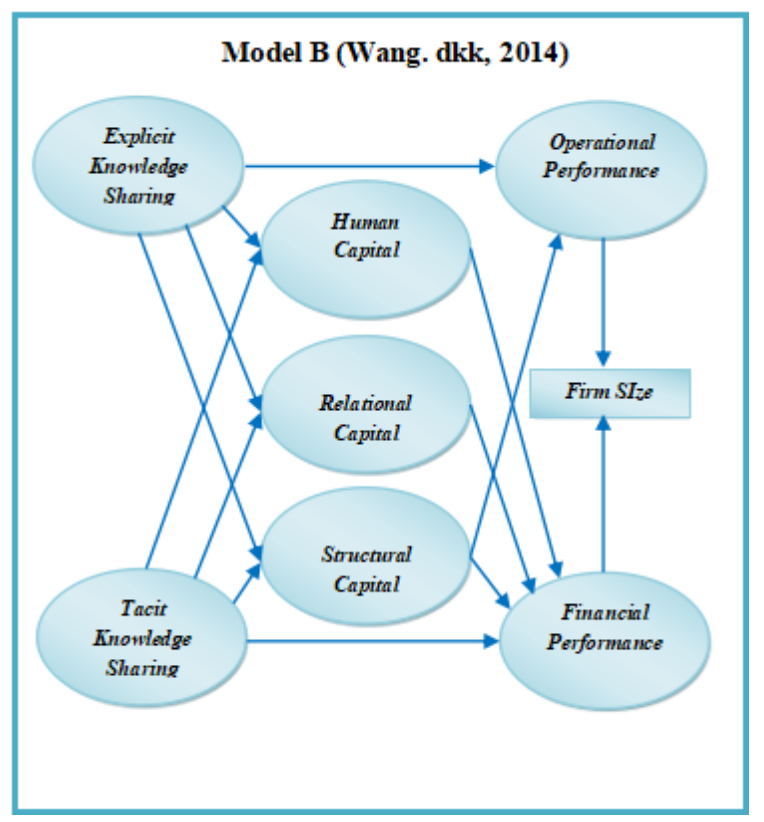

Gambar 2. "Knowledge sharing, intellectual capital and firm performance" (Wang dkk, 2014).

Dengan demikian, berdasarkan penelitian ini akan mengembangkan adanya pengaruh tacit knowledge sharing dan explicit knowledge sharing terhadap kinerja IKM di Indonesia. Penelitian ini akan melibatkan tiga variabel meliputi : tacit knowledge sharing dan explicit knowledge sharing. serta organizational performance.
Ayu Endah Wahyuni

Jurnal Ilmiah Teknologi Informasi Terapan Volume V, No. 1, 15 Desember 2018 


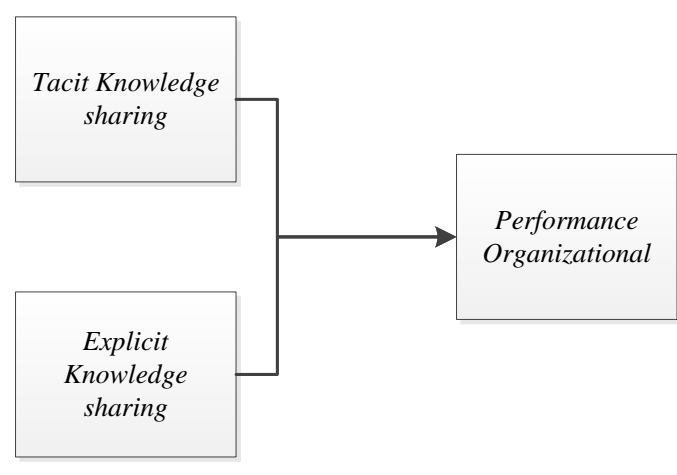

Gambar 3. Model Reseacrh

Penelitian ini akan menguji pengaruh pengaruh tacit knowledge sharing dan explicit knowledge sharing terhadap kinerja IKM di Indonesia. Apakah kedua variabel tersebut mempengaruhi peningkatann terhadap kinerja IKM.a

\section{KESIMPULAN}

Penelitian ini mengembangkan suatu model dengan mengintegrasikan tacit knowledge sharing dan explicit knowledge sharing terhadap organizational performance di Industri Kecil Menengah (IKM) di Indonesia.. Hasil penelitian ini menggambarkan hubungan antara tacit knowledge sharing dan explicit knowledge sharing terhadap organizational performance. Adanya pengaruh tacit dan explicit knowledge dalam IKM dapat mempengaruhi kinerja IKM di Indonesia menjadi lebih baik dalam berdaya saing.

\section{REFERENCES}

Abeson, F., \& Taku, M. A. (2009). Knowledge source and small business competitiveness. Competitiveness Review: An International Business Journal , pp. 88-95.

Agha, S., \& Alrubaiee, L. (2012). Effect of core Competence on Competitive Advantage and Organizational. International Journal of Business and Management, 192-204.

Barney, J. (1991). Film Resource and Sustained Competitive Advantage. Journal of Management , 99-120.

Borges, R. (2013). Tacit knowledge sharing between
IT workers. Management Research Review, Vol. 36 No. 1.

Dhanaraj, C., Lyles, M. A., Steensma, K. H., \& Tihanyi, L. (2004). Managing tacit and explicit knowledge transfer in IJVs: the role of relational embeddedness and the impact on performance. Journal of International Business Studies , 428-442.

Djibril, M. (2013, 9 17). Industri Karet Menjanjikan. (Harian Republika) Retrieved 5 11, 2014, from Republika Online: http://www.republika.co.id/berita/ekonomi/m akro/13/09/17/mt9xz0-kemenperin-industrikreatif-beri-sumbangan-bagi-perekonomiannasional

Egbu, O. C., Hari, S., \& Renukappa, H. S. (2005). Knowledge management for sustainable competitivenss in small and medium surveying practise. 23(1) (7-21).

Gharakhani, D., \& Mousakhani, M. (2011). Knowledge Management Capabilities and SME's Organizational Performance. Journal of Chinese Entrepreneurship , 35-49.

Gharakhani, D., \& Mousakhani, M. (2012). Knowledge management capabilities and SME's Organizational Performance. Journal of Chinese Entrepreneurship , 35-49.

Haag, M., Duan, Y., \& Mathews, B. (2010). The Impact of Culture on the Application of the SECI Model. IGI Globa , (26-47) DOI: 10.4018/978-1-60566-790-4.ch002.

Haron, H. (2005). Conceptualization of Tacit Knowledge Dimension. Proceedings of The Postgraduate Annual Research Seminar, (pp. 12-17).

Hoffman, N. P. (2000). An Examination of "Sustainable Competitie Advantage" Concept : Past, Present, and Future. Academy of Marketing Science Review, Volume 4.

Hong, H.-K., Kim, J.-S., Kim, T., \& Leem, B.-H. (2008). Theeffect of knowledge on system integration project performance. Industrial Management \& Data Systems, pp. 385-404.

Hourlay, S. (2004). Tacit Knowledge : the variety of meaning in empirical research, Master 
Thesis. Kingston Business School .

Hubeis, M. (2011). Program Studi Industri Kecil Menengah (PS MPI). Retrieved 5 11, 2014, from Program Studi Industri Kecil Menengah (PS MPI) website: http://mpi.ipb.ac.id/

Jackson, D. N. (2012). Using Tacit Knowledge for Competitive Advantage : A Study of Sales Team Performance. Indiana University Purdue University Fort Wayne: Opus: Research \& Creativity at IPFW.

Kamukama, N., Ahiauzu, A., \& Ntayi, J. M. (2011). Competitive advantage : mediator of intellectual capital and performance. Journal of Intellectual Capital , 152-164.

Koskinen, K. U. (2001). Tacit Knowledge as a Promoter of Success in Technology Firm. Proceedings of the 34th Hawaii International Conference on System Sciences , (pp. 1-9). Hawaii, U.S.

Lee, C. K., Foo, S., \& Goh, D. (2006). On the concept and types of knowledge. Journal of Information \& Knowledge Management , $5(2)$, $151-163$. doi:10.1142/S0219649206001402.

Lemhannas. (2012). Peningkatan Daya Saing Industri Indonesia. Jurnal Kajian Lemhannas RI , Edisi 14 Halaman 44.

Manurung, M. (2010). ACFTA dan Ancaman Kedaulatan. Jurnal Sosial Demokrasi , 13.

Manurung, Mian; dkk. (2010). Perdagangan bebas ASEAN-Cina (Berdagang untuk siapa?). 8.

Maulana, A. G. (2014, 3 3). Pertumbuhan IKM Kuartal I/2014 Hanya 4\%. Retrieved 5 14, 2014, from http://bandung.bisnis.com/: http://bandung.bisnis.com/read/20140303/34 229/499711/pertumbuhan-ikm-kuartal-i2014hanya-4

Mládková, L. (2012). SHARING TACIT KNOWLEDGE WITHIN ORGANIZATIONS: EVIDENCE FROM THE CZECH REPUBLIC. 6 (2).

Ngah, R., \& Jusoff, K. (2009). Tacit Knowledge Sharing and SME's Organizational Performance. 1 no. 1.

Ngah, Rohana; Ibrahim, Abdul Razak. (2008). The
Impact of Intellectual Capital and Tacit Knowledge sharing on Organizational Performance: A Preliminary Study of Malaysian SMEs. 5th International Conference on Intellectual Capital, Knowledge Management \& Organisational Learning (hal. 369). New York: Academic Publishing Limited.

Nonaka, I. (1998). The knowledge-creating company.

Nonaka, I., \& Konno, I. (1998). The concept of 'Ba': Building a foundation for knowledge creation. California Management Review, 40(3), 40-54.

Nonaka, I., \& Takeuchi, H. (1995). The Knowledge Creating Company: How Japanese Companies Create the Dynamics of Innovation.

Nooteboom, B. (1999). Innovation, learning, and industrial organization. 23(2) (127-150).

Retraubun, A. S. (2013, 12 3). Hadapi MEA 2015, Kemperin Tingkatkan Daya Saing IKM. Retrieved 5 15, 2014, from http://www.beritasatu.com/: http://www.beritasatu.com/ekonomi/153381 hadapi-mea-2015-kemperin-tingkatkan-dayasaing-ikm.html

Rumanti, A. A. (2009). Analisis Korelasi Individual Tacit Knowledge dengan Competitive Advantage. Bandung: Institut Teknologi Bandung.

Schwab, K. (2013). The Global Competitiveness Report 2013-2014. Geneva: the World Economic Forum.

Small, C. T., \& Sage, A. P. (2006). Knowledge Management and Knowledge Sharing: a Review . 5 (153-69).

Starzynska, B. (2006). Knowledge Conversion in Teamwork with Usage of Quality Tools. Poznan University of Technology.

Vail, E. F. (1999). Knowledge mapping: Getting started with knowledge management. 16(4) (16-23).

Wang, J., Zhao, S., \& Yang, J. (2004). Study on the Cultivation of Core Competence Based on Tacit Knowledge.
Ayu Endah Wahyuni

Jurnal Ilmiah Teknologi Informasi Terapan

Volume V, No. 1, 15 Desember 2018 
Wang, Z., Wang, N., \& Liang, H. (2014). Knowledge sharing, intellectual capital and firm performance. Emerald Group Publishing Limited, Vol. 52 No. 2.

Wiyanto. (2014, 3 19). Daya Saing Indonesia Masih Rendah. Retrieved 5 15, 2014, from ekonomi.inilah.com: http://ekonomi.inilah.com/read/detail/208430 3/daya-saing-indonesia-masihrendah\#.U3Q3L_mSzkU 